\title{
The changing pattern of nontuberculous mycobacterial disease
}

\author{
Joseph O Falkinham III PhD
}

JO Falkinham III. The changing pattern of nontuberculous mycobacterial disease. Can J Infect Dis 2003;14(5):281-286.

Nontuberculous mycobacteria are human opportunistic pathogens whose source of infection is the environment. These include both slow-growing (eg, Mycobacterium kansasii and Mycobacterium avium) and rapid-growing (eg, Mycobacterium abscessus and Mycobacterium fortuitum) species. Transmission is through ingestion or inhalation of water, particulate matter or aerosols, or through trauma. The historic presentation of pulmonary disease in older individuals with predisposing lung conditions and in children has been changing. Pulmonary disease in elderly individuals who lack the classic predisposing lung conditions is increasing. Pulmonary disease and hypersensitivity pneumonitis have been linked with occupational or home exposures to nontuberculous mycobacteria. There has been a shift from Mycobacterium scrofulaceum to M avium in children with cervical lymphadenitis. Further, individuals who are immunosuppressed due to therapy or HIV-infection are at a greatly increased risk for nontuberculous mycobacterial infection. The changing pattern of nontuberculous mycobacterial disease is due in part to the ability of these pathogens to survive and proliferate in habitats that they share with humans, such as drinking water. The advent of an aging population and an increase in the proportion of immunosuppressed individuals suggest that the prevalence of nontuberculous mycobacterial disease will increase.

Key Words: Epidemiology; Mycobacterial; Physiology; Risk Factors

$\mathrm{N}$ ontuberculous mycobacteria is a collective term for different species of the genus Mycobacterium that do not belong to the Mycobacterium tuberculosis complex. In the past they have been referred to as atypical mycobacteria and as mycobacteria other than tuberculosis. They are also opportunistic pathogens, causing a range of diseases in humans (Table 1). In the absence of evidence of person-to-person transmission, it has been proposed that the source of infection by nontuberculous mycobacteria is the environment (1). Representatives of many species have been recovered from environmental samples such as water, soil and aerosols (2), and DNA fingerprints have been shown to be identical between patient and environmental isolates (3). Although notification of nontuberculous mycobacterial disease is not required, it has been reported that the prevalence of disease is increasing $(4,5)$. Because the habitats occupied by nontuberculous mycobacteria (eg, drinking water) are also shared by humans, and because

\section{L'évolution de la mycobactériose non tuberculeuse}

Les mycobactéries non tuberculeuses sont des anthropathogènes opportunistes dont la source d'infection se trouve dans l'environnement. Elles incluent à la fois des espèces à croissance lente (p. ex., Mycobacterium kansasii et Mycobacterium avium) et à croissance rapide (p. ex., Mycobacterium abcessus et Mycobacterium fortuitum). La transmission se fait par l'ingestion ou l'inhalation d'eau, de particules ou d'aérosols ou par un traumatisme. L'anamnèse de la pneumopathie chez les personnes âgées atteintes d'une affection pulmonaire favorisante et chez les enfants se modifie. La pneumopathie est en hausse chez les personnes âgées ne présentant pas une affection pulmonaire favorisante classique. La pneumopathie et la pneumopathie d'hypersensibilité s'associent à une exposition à des mycobactéries non tuberculeuses au travail ou au domicile. On remarque une transition des Mycobacterium scrofulaceum aux $M$ avium chez les enfants atteints d'une lymphadénite cervicale. De plus, les individus immunosupprimés en raison d'un traitement anti-VIH affichent un risque beaucoup plus élevé d'infection mycobactérienne non tuberculeuse. L'évolution de la mycobactériose non tuberculeuse est imputable, en partie, à la capacité de ces pathogènes de survivre et de proliférer dans des habitats qu'ils partagent avec les humains, tels que l'eau potable. La population vieillissante et l'augmentation de la proportion d'individus immunosupprimés laissent supposer que la prévalence de mycobactériose non tuberculeuse augmentera.

the number of individuals with heightened susceptibility to mycobacterial disease is increasing (eg, through immunosuppression), it is likely that the prevalence of disease caused by nontuberculous mycobacteria will increase. This increase, coupled with the broad-spectrum antibiotic resistance of these opportunistic pathogens, will continue to create difficulties. This brief review will focus on the changing pattern of nontuberculous mycobacterial disease with reference to the ecology of this group of opportunistic human pathogens.

\section{HISTORICAL CHARACTERISTICS OF} NONTUBERCULOS MYCOBACTERIAL DISEASE Historically, the majority of reports of nontuberculous mycobacterial disease have been in white males above the age of 60 who had some predisposing lung condition (1). These conditions included pneumoconiosis, chronic obstructive pulmonary disease and black lung, and infection was associated

\footnotetext{
Department of Biology, Virginia Polytechnic Institute and State University, Blacksburg, Virginia 24061-0346, United States

Correspondence and reprints: Dr JO Falkinham, Department of Biology, Virginia Tech, Blacksburg, Virginia 24061-0406. Telephone 540-231-

5931, fax 540-231-9307, e-mail jofiii@vt.edu
} 
TABLE 1

Diseases caused by nontuberculous mycobacteria

\begin{tabular}{ll}
\hline Disease & Risk factors \\
\hline Pulmonary disease & Pneumoconiosis, COPD, black lung \\
& Aerosols (occupational exposure) \\
& Aerosols (hot tubs and spas) \\
& Elderly, absence of predisposing factors \\
Hypersensitivity pneumonitis & Aerosols (occupational exposure) \\
Cervical lymphadenitis & Infancy (age 6-24 months) \\
Disseminated infection & HIV infection; AIDS \\
& Immunosuppression (transplantation) \\
& Immunosuppression (chemotherapy)
\end{tabular}

COPD Chronic obstructive pulmonary disease

with work in occupations where dust was generated (eg, farming and coal mining) or with smoking $(1,6)$. It was not uncommon to have nontuberculous mycobacteria disease described as a 'rural' disease, as opposed to tuberculosis, caused by Mycobacterium tuberculosis, which was described as an 'urban' disease (7-9). The most prevalent species in the United States included Mycobacterium kansasii, Mycobacterium avium and Mycobacterium intracellulare (1). Added to that list in Canada was Mycobacterium xenopi (6). In addition to older men, nontuberculous mycobacteria were shown to be responsible for cervical lymphadenitis in children (1). In children, the predominant mycobacterial species isolated from the infected lymph nodes was Mycobacterium scrofulaceum until approximately 1980, when M avium became the predominant species (10). Nontuberculous mycobacterial infections caused by $M$ kansasii or $M$ avium were found in patients that had undergone organ transplantation and who therefore had suppressed immune responses (11).

Care must be taken in placing too much faith in the mycobacterial species assignments made before 1985 . Mycobacterial taxonomy developed slowly and it is only recently that methods for accurate species identification (eg, DNA probe, 16S rRNA gene sequence) of both the slow- (12) and rapid-growing (13) species have become available. For example, until the development of DNA-based methods, it was impossible to distinguish $\mathrm{M}$ avium from $\mathrm{M}$ intracellulare by cultural, biochemical or enzymatic tests (12). As a result, investigators, including the present author, have grouped the strains together and reported them as $M$ avium-intracellulare (an unacceptable assignment) or M avium complex. Although use of the designation ' $\mathrm{M}$ avium complex' is acceptable on taxonomic grounds, it hides the unique epidemiological features of each species.

A variety of risk factors have been associated with nontuberculous mycobacterial disease, including predisposing lung conditions (1,6) and immunosuppression (11). One of the major historical concerns was whether or not recovery of one of the nontuberculous mycobacteria indicated an infection requiring treatment. It was known that nontuberculous mycobacteria could be recovered from environmental samples (eg, water and soil) yet, in the absence of knowledge of virulence factors, the significance of isolation from a patient was debatable $(1,14)$. Because prevention and treatment of nontuberculous mycobacterial infection may require a multipleantibiotic regimen (14-16) with its attendant side effects, a decision to treat patients has to be carefully made. The general consensus was that clinical symptoms consistent with tuberculosis in conjunction with repeated isolation of a nontuberculous mycobacterium in significant numbers (ie, greater than several colonies) was evidence of infection by that species $(1,14)$. In spite of the fact that nontuberculous mycobacterial disease was not reportable, as time wore on it became clear that a wide variety of nontuberculous mycobacteria species, including the rapid-growing mycobacteria (13), caused serious, life-threatening pulmonary disease.

\section{NONTUBERCULOUS MYCOBACTERIAL DISEASE IN THE AIDS ERA}

In 1982, the first reports appeared of disseminated $M$ avium infection (ie, bacteremia) in patients with profound immunodeficiency (17). These patients were infected with HIV (Table 1). In the terminal stages of AIDS, when CD4+ lymphocyte counts fall below 100, nontuberculous mycobacteria disease appears and the bacteria can be isolated from blood, tissue, sputum and fecal samples $(18,19)$. M avium is the most frequently isolated species, although other nontuberculous mycobacteria are also isolated. Interestingly, although $\mathrm{M}$ avium and $M$ intracellulare occurred at approximately the same frequency in the classic pulmonary presentation in men (1), M intracellulare was rarely recovered from AIDS patients (20).

The advent of large numbers of $M$ avium-infected AIDS patients, placed great demands on microbiology laboratories, especially the state tuberculosis labs that performed the bulk of the work. It became quickly apparent that knowledge of nontuberculous mycobacterial epidemiology and taxonomy was weak, and that improved methods for isolating and identifying these pathogens was needed. This led to the development of improved methods for their isolation (21) and identification (12), antibiotic-susceptibility testing $(22,23)$ and regimens for antimicrobial therapy (14-16). In addition, basic studies of ecology, physiology and genetics were initiated and continue to this day (2).

The improved methods for isolation of mycobacteria from patient samples led to the identification of novel mycobacterial species from both patients and the environment. Since 1985, more than 30 newly recognized mycobacterial species have been described (12).

\section{PHYSIOLOGICAL ECOLOGY OF NONTUBERCULOUS MYCOBACTERIA}

Physiological ecology is the study of the physiological characteristics of a microorganism that are determinants of its ecology and transmission. A large number of nontuberculous mycobacterial species have been recovered from natural water, drinking water, soil, dust and aerosol samples (2). Nontuberculous mycobacteria are normal inhabitants of these habitats; they are not contaminants from some other source. For example, a single clone of $\mathrm{M}$ avium was shown to persist in the water system of a hospital for over 18 months (3). For some species, particularly $M$ avium and $M$ intracellulare, some physiological determinants of their distribution in the environment have been identified (Table 2). One of the more interesting questions concerning the slow-growing mycobacteria (eg, $M$ kansasii and $M$ avium), is how they can persist in the environment. They logically ought to be washed out. The answer is that they are hydrophobic due to the presence, in part, of a lipid- and wax-rich cell wall. Their hydrophobic interactions results in their attachment to surfaces to form biofilms in drinking water pipes (24) or in catheters (25). In addition, 
TABLE 2

Physiological ecology of $M$ avium and $M$ intracellulare

\begin{tabular}{|c|c|}
\hline Feature & Epidemiological ramifications \\
\hline Slow growth & Broad antimicrobial resistance \\
\hline Lipid-rich cell wall & Impermeable, hydrophobic, antimicrobial resistance \\
\hline Hydrophobic & $\begin{array}{l}\text { Impermeable to hydrophilic compounds, aggregation, } \\
\text { concentration at air-water interface, biofilm formation }\end{array}$ \\
\hline Oligotrophic & Grow at low nutrient concentrations \\
\hline Microaerobic & Grow at $6 \%$ oxygen \\
\hline Acidophilic & Grow at $\mathrm{pH} 5-6$ \\
\hline
\end{tabular}

hydrophobic interactions results in mycobacterial concentration at the air-water interface in bodies of water (26) and the aerosolization of the slow-growing mycobacteria in droplets of a size that is able to enter the human alveoli (27). The nontuberculous mycobacteria's broad spectrum resistance to antimicrobial agents (28), including chlorine (29), coupled with their ability to grow at low nutrient concentrations (ie, oligotrophy [30]) is likely responsible for their increase in number in drinking water distribution systems (24). Human activities (eg, increased use of disinfectants in water treatment) coupled with the nontuberculous mycobacteria's inherent resistance to disinfectants and their ability to grow in drinking water systems, will lead to selection and proliferation of mycobacteria in environments shared by humans and mycobacteria (ie, drinking water).

\section{CHANGES IN THE PRESENTATION OF NONTUBERCULOUS MYCOBACTERIAL DISEASE}

Over the past decade, there have been a number of significant changes in the presentation of nontuberculous mycobacterial disease (Table 3). These include cervical lymphadenitis in children, pulmonary disease in the elderly and pulmonary disease in persons in occupations and at home.

\section{Cervical lymphadenitis in children}

Before the period of 1975 to 1985, almost all cases of cervical lymphadenitis in children were caused by $M$ scrofulaceum, a pigmented, a relatively fast growing, slow-growing mycobacterium $(1,31)$. However, since this period, almost all cases have been caused by $M$ avium $(10,31)$. This change has occurred in the United States (10), Britain (31) and Australia (32). In Texas, there was an earlier shift (1960 to 1980) from M kansasii to $M$ avium (33). The shift was not due to a change in laboratory techniques, because these species are easily distinguished and isolation methods have not changed (10). Because the most likely route of infection is oral from water, the shift may be due to a change in the prevalence of $M$ scrofulaceum (M kansasii in Texas) in water. In the 1975 to 1980 time period, M scrofulaceum numbers in United States water samples were higher than $M$ avium (34). This is no longer the case. In a recent survey, $M$ scrofulaceum was almost never recovered from American water samples (24). It is not known whether M scrofulaceum has disappeared from the water in other countries (eg, Britain and Australia). Any explanation for the shift to M avium must account for the occurrence of the shift over the same time period in widely separated developed countries.

\begin{tabular}{|c|c|}
\hline Disease & New presentation \\
\hline Cervical lymphadenitis in children & $M$ avium replaced $M$ scrofulaceum \\
\hline $\begin{array}{l}\text { Pulmonary mycobacteriosis in the } \\
\text { elderly }\end{array}$ & Absence of classic risk factors \\
\hline Hypersensitivity pneumonitis & $\begin{array}{l}\text { Following ccupational exposure to } \\
\text { aerosols, metalworking fluid } \\
\text { aerosols, and/or indoor swimming } \\
\text { pool aerosols }\end{array}$ \\
\hline Pulmonary mycobacteriosis & Exposure to hot tubs and spas \\
\hline
\end{tabular}

Pulmonary disease in the elderly

A new group of patients with pulmonary disease caused by nontuberculous mycobacteria have been defined by their lack of risk factors that predispose one to mycobacterial infection (35). The patients, primarily slight, elderly women, are nonsmokers, without a history of occupational exposure to dusts and lack the known predisposing lung conditions (eg, pneumoconiosis, black lung) $(4,5,35)$. The number of such patients appears to be increasing $(4,5)$, however, it is not known whether that is due to a real increase in incidence or to increased awareness. Current investigations are directed at identifying the source of infection and determining whether the patients have any previously unknown underlying conditions that predisposes one to mycobacterial infection. Such a condition may be only expressed in the elderly. The authors are currently investigating two sources of infection: exposure to mycobacterial-laden aerosols in showers and exposure to mycobacterial-rich dusts generated from peat moss. Mycobacteria, including $M$ avium and $M$ intracellulare, have been recovered from hot and cold water in showers and from showerheads. Based on a report of the high frequency of recovery of mycobacteria, including $M$ avium and $M$ intracellulare, from potting soils (36), we have recovered mycobacteria from dusts generated by peat moss or potting soil samples from patients. A wide variety of mycobacteria have been recovered that are associated with particles small enough to enter the human alveoli. The water and potting soil-aerosol isolates that belong to the same species are currently being typed to determine whether the patient and environmental isolates share the same DNA fingerprint.

Hypersensitivity pneumonitis associated with occupations There have been reports of hypersensitivity pneumonitis (HP) associated with occupational aerosol exposures in automobile factories $(37,38)$ and indoor swimming pools (39). Individuals with HP in occupations in both environments shared a common history of exposure to aerosols generated from solutions that contained mycobacteria (40-42). Further, mycobacteria are capable of inducing inflammatory reactions, including nitric oxide, interferon-gamma, and interleukin- 6 and -12 secretion (43). In the automobile industry, HP follows exposure to aerosols generated during metalworking operations $(37,38)$. Metalworking fluid, an emulsion of organic compounds and water (44), is sprayed on cutting tools and that generates the aerosol. Mycobacteria are capable of utilizing the organic compounds in metalworking fluid for growth $(45,46)$ and are resistant to the disinfectants (eg, quaternary ammonium 
TABLE 4

Factors contributing to changes in nontuberculous mycobacterial disease

\begin{tabular}{|c|c|}
\hline Factor & $\begin{array}{l}\text { Effect on nontuberculous } \\
\text { mycobacterial disease }\end{array}$ \\
\hline Microbial adaptation & $\begin{array}{l}\text { Adapt to survival in the presence of } \\
\text { antimicrobials }\end{array}$ \\
\hline Changes in human susceptibility & Increase in immunodeficient host \\
\hline Changing ecosystems & Increased demand for water \\
\hline Changing human demographics & $\begin{array}{l}\text { Aging population of increased } \\
\text { susceptibility }\end{array}$ \\
\hline Land use & $\begin{array}{l}\text { Increased opportunity for transmission / } \\
\text { new environments for mycobacterial } \\
\text { growth }\end{array}$ \\
\hline Travel & $\begin{array}{l}\text { Worldwide transmission of novel } \\
\text { mycobacteria }\end{array}$ \\
\hline Breakdown of public health & $\begin{array}{l}\text { Inability to monitor mycobacterial } \\
\text { disease outbreaks }\end{array}$ \\
\hline Poverty & $\begin{array}{l}\text { Increase in susceptible hosts, } \\
\text { less access to care }\end{array}$ \\
\hline War, dislocation and famine & $\begin{array}{l}\text { Increase in susceptible hosts, } \\
\text { less access to care, greater } \\
\text { opportunity for transmission }\end{array}$ \\
\hline
\end{tabular}

Data from reference 56

compounds) used to inhibit microbial growth in metal working fluid (47). A novel species, Mycobacterium immunogenum, has been recovered from metalworking fluid (48).

Infections associated with hot tubs and spas

Recently there have been reports of $M$ avium and nontuberculous pulmonary disease associated with exposure to home hot tubs and spas (49). $M$ avium has been isolated from both hot tubs and spas, and from patients who used the tubs and were exposed to aerosols $(50,51)$. The hot tubs and spas can generate bubbles and aerosols. Mycobacteria, including $M$ avium, are concentrated by bubbles and droplets ejected from water (27). Mycobacteria, particularly M avium, can persist in the spas and hot tubs because of their ability to grow at low organic matter concentrations $(24,30)$ and their chlorine-resistance (29).

\section{HYPOTHESIS ON THE ACQUISITION OF INFECTION BY M AVIUM}

In spite of the fact that high numbers of $M$ avium have been detected in environmental samples, there have been few instances where $M$ avium isolates from the environment have been shown to share identical DNA fingerprint patterns with isolates from patients. This has been the case even when the patient was exposed (eg, drank or showered) to the environmental sample (eg, water) that yielded $M$ avium. There are several possible explanations for the low frequency of matches. First, the infecting $M$ avium strain was present in the environment, but the wrong sample was collected, the numbers were too low for reliable recovery, or the wrong mycobacterial colony was isolated. Nontuberculous mycobacteria are present in substantial numbers in the environment (2) and even within a single species, a diversity of types is found $(52,53)$. Second, the patient was infected with more than a single $M$ avium clone (polyclonal infection) and representatives of other clones were not recovered. Polyclonal infection is common in patients and approximately $25 \%$ of AIDS patients are infected with more than a single clone of $\mathrm{M}$ avium $(52,54)$.

Another possibility is that there exist different pathways for disease acquisition. Individuals could be colonized by $M$ avium during childhood without any signs of disease. A proportion of such patients might show evidence of infection, such as a positive mycobacterial skin test (1). Following childhood colonization, a later change in the patient's health status (eg, immunodeficiency) could lead to disease. Unless the individual remained in the same location (ie, environment) from childhood to the onset of $\mathrm{M}$ avium disease, it would be unlikely that DNA fingerprints of patient and environmental isolates would match. This is a consequence of the wide variation in the genetic types represented by $M$ avium isolates recovered from the environment $(52,53)$.

If individuals were not colonized by $M$ avium, exposure, infection and disease may occur either because of an overwhelming exposure or an existing predisposing condition. In these cases, there may be a DNA fingerprint match between patient and environmental isolates. However, these matches might be rare. The presence of $M$ avium in many environments that are used by humans (eg, drinking water) means that colonization by $M$ avium is likely and widespread $(24,55)$. As a consequence, it would be expected that DNA fingerprint matches between patients and environmental isolates would be rare. Matches would be limited to those instances where the patient was not colonized or where the patient was colonized, but infected by another, more virulent $M$ avium that became the predominant member of the population.

\section{THE FUTURE EPIDEMIOLOGY OF NONTUBERCULOUS MYCOBACTERIAL DISEASE}

Recently, the Institute of Medicine identified 13 factors that were responsible for the appearance of new infectious diseases throughout the world (56). A number of those factors would likely lead to an increase in the prevalence and incidence of nontuberculous mycobacterial disease (Table 4). One factor that will have an impact on nontuberculous mycobacterial disease involves overlaps between human and mycobacterial ecology. Mycobacteria and humans share the water supply. The need to reduce the incidence of water-associated gastro-intestinal disease has led to a widespread implementation of disinfection of drinking water (57). One consequence of this effort is selection for disinfectant-resistant mycobacteria that can grow in the limited organic matter in water made available by the death of microbial competitors. The presence of mycobacteria in drinking water (24) and thisconcentration in hospital hot water systems (58), coupled with an aging human population (changing demographics) and increases in the proportion of the population that are immunodeficient (changing human susceptibility) may place more individuals at risk for nontuberculous mycobacterial disease.

ACKNOWLEDGEMENTS: The author gratefully acknowledges the discussions concerning the acquisition of nontuberculous mycobacterial disease with Dr Joel Maslow of the University of Pennsylvania School of Medicine and Dr Ford von Reyn of the Dartmouth-Hitchcock School of Medicine. Research in the author's laboratory has been supported by the National Institutes of Health, American Water Works Association Research Foundation, the Heiser Foundation and the Potts Foundation. 


\section{REFERENCES}

1. Wolinsky E. Nontuberculous mycobacteria and associated diseases. Am Rev Resp Dis 1979;119:107-59.

2. Falkinham JO III. The epidemiology of infection by nontuberculous mycobacteria. Clin Microbiol Revs 1996;9:177-215.

3. von Reyn CF, Maslow JN, Barber TW, Falkinham JO III, Arbeit RD. Persistent colonisation of potable water as a source of Mycobacterium avium infection in AIDS. Lancet. 1994;343:1137-41.

4. Reich JM, Johnson RE. Mycobacterium avium complex pulmonary disease. Incidence, presentation, and response to therapy in a community setting. Am Rev Respir Dis 1991;143:1381-5.

5. Kennedy TP, Weber DJ. Nontuberculous mycobacteria. An underappreciated cause of geriatric lung disease. Am J Respir Crit Care Med 1994;149:1654-8.

6. Contreras MA, Cheung OT, Sanders DE, Goldstein RS. Pulmonary infection with nontuberculous mycobacteria. Am Rev Respir Dis 1988;137:149-52.

7. Ahn CH, Lowell JR, Onstad GD, Shuford EH, Hurst GA. A demographic study of disease due to Mycobacterium kansasii or M intracellulare-avium in Texas. Chest 1979;75:120-5.

8. Kim, TC, Arora NS, Aldrich TK, Rochester DF. Atypical mycobacterial infections: A clinical study of 92 patients. So Med J 1981;74:1304-8.

9. Choudhri S, Manfreda J, Wolfe J, Parker S, Long R. Clinical significance of nontuberculous mycobacteria isolates in a Canadian tertiary care center. Clin Infect Dis 1995;21:128-33.

10. Wolinsky, E. Mycobacterial lymphadenitis in children: A prospective study of 105 nontuberculous cases with long-term follow-up. Clin Infect Dis 1995;20:954-63.

11. Simpson GL, Raffin TA, Remington JS. Association of prior nocardiosis and subsequent occurrence of nontuberculous mycobacteriosis in a defined, immunosuppressed population. J Infect Dis 1982;146:211-9.

12. Tortoli E. Impact of genotypic studies on mycobacterial taxonomy: The new mycobacteria of the 1990s. Clin Microbiol Revs 2003;16:319-54.

13. Wallace RJ Jr. Recent changes in taxonomy and disease manifestations of the rapidly growing mycobacteria. Eur J Clin Microbiol Infect Dis 1994;13:953-60.

14. Wallace RJ Jr, O’Brien R, Glassroth J, Raleigh, J, Dutt A. Diagnosis and treatment of disease caused by nontuberculous mycobacteria. Am Rev Respir Dis 1990;142:940-53.

15. Masur H. Recommendation on prophylaxis and therapy or disseminated Mycobacterium avium complex disease in patients infected with the human immunodeficiency virus. N Eng J Med 1993;329:898-904.

16. Griffith DE, Wallace RJ Jr. New developments in the treatment of nontuberculous mycobacterial (NTM) disease. Sem Respir Infect 1996;11:301-10.

17. Zakowski P, Fligiel S. Berlin OGW, Johnson BL. Disseminated Mycobacterium avium-intracellulare infection in homosexual men dying of acquired immunodeficiency. J Am Med Assoc 1982;248:2980-2.

18. Hosburgh CR, Havlik JA, Ellis DA, et al. Survival of patients with acquired immune deficiency syndrome and disseminated Mycobacterium avium complex infection with and without antimycobacterial chemotherapy. Am Rev Respir Dis 1991;144:557-9.

19. Nightingale SD, Byrd LT, Southern PM, Jockusch JD, Cal SX, Wynne BA. Incidence of Mycobacterium avium-intracellulare complex bacteremia in human immunodeficiency virus-positive patients. J Infect Dis 1992;165:1082-5.

20. Drake TA, Herron RM Jr, Hindler JA, Berlin OGW, Bruckner DA. DNA probe reactivity of Mycobacterium avium complex isolates from patients without AIDS. Diagn Microbiol Infect Dis 1988;11:125-8.

21. Havlir D, Kemper CA, Deresinski SC. Reproducibility of lysiscentrifugation cultures for quantification of Mycobacterium avium complex bacteremia. J Clin Microbiol 1993;31:1794-8.

22. Inderlied CB, Young LS, Yamada JK. Determination of in vitro susceptibility of Mycobacterium avium complex isolates to antimycobacterial agents by various methods. Antimicrob Agents Chemother 1987;31:1697-702.

23. Woods GL, Bergmann JS, Witebsky FG, et al. Multisite reproducibility of results obtained by the broth microdilution method for susceptibility testing of Mycobacterium abscesus, Mycobacterium chelonae, and Mycobacterium fortuitum. J Clin Microbiol 1999;37:1676-82.
24. Falkinham JO III, Norton CD, Le Chevallier MW. Factor influencing numbers of Mycobacterium avium, Mycobacterium intracellulare, and other mycobacteria in drinking water distribution systems. Appl Environ Microbiol 2001;67:1225-31.

25. Schelonka RL, Ascher P, McMahon DP, Drehner DM, Kuski MR. Catheter-related sepsis caused by Mycobacterium avium complex. Ped Infect Dis J 1994;13:236-8.

26. Wendt SL, George KL, Parker BC, Gruft H, Falkinham JO III. Epidemiology of infection by nontuberculous mycobacteria. III. Isolation of potentially pathogenic mycobacteria in aerosols. Am Rev Respir Dis 1980;122:259-63.

27. Parker BC, Ford MA, Gruft H, Falkinham JO III. Epidemiology of infection by nontuberculous mycobacteria. IV. Preferential aerosolization of Mycobacterium intracellulare from natural water. Am Rev Respir Dis 1983;128:652-6.

28. Rastogi N, Frehel C, Ryter A, Ohayon H, Lesourd M, David HL. Multiple drug resistance in Mycobacterium avium: Is the wall architecture responsible for the exclusion of antimicrobial agents. Antimicrob Agents Chemother 1981;20:666-77.

29. Taylor RH, Falkinham JO III, Norton CD, LeChevallier MW. Chlorine, chloramine, chlorine dioxide, and ozone susceptibility of Mycobacterium avium. Appl Environ Microbiol 2000;66:1702-5.

30. George KL, Parker BC, Gruft H, Falkinham JO III. Epidemiology of infection by nontuberculous mycobacteria. II. Growth and survival in natural waters. Am Rev Respir Dis 1980;122:89-94.

31. Colville A. Retrospective review of culture-positive mycobacterial lymphadenitis cases in children in Nottingham, 1979-1990. Eur J Clin Microbiol Infect Dis 1993;12:192-5.

32. Joshi W, Davidson PM, Jones PG, Campbell PE, Roberton DM. Nontuberculous mycobacterial lymphadenitis in children. Eur J Pediatr 1989;148:751-4.

33. Schaad UB, Votteler TP, McCracken GH, Nelson JD. Management of atypical mycobacterial lymphadenitis in childhood: A review based on 380 cases. J Pediatr 1979;95:356-60.

34. Falkinham JO III, Parker BC, Gruft H. Epidemiology of infection by nontuberculous mycobacteria. I. Geographic distribution in the eastern United States. Am Rev Respir Dis 1980;121:931-7.

35. Prince DS, Peterson DD, Steiner RM, et al. Infection with Mycobacterium avium complex in patients without predisposing conditions. N Engl J Med 1989;321:863-8.

36. Yajko DM, Chin DP, Gonzalez PC, et al. Mycobacterium avium complex in water, food, and soil samples collected from the environment of HIV-infected individuals. J AIDS Hum Retrovirol 1995;9:176-82.

37. Bernstein DI, Lummus ZL, Santilli G, Siskosky J, Bernstein IL. Machine operator's lung. A hypersensitivity pneumonitis disorder associated with exposure to metalworking fluid aerosols. Chest 1995; 108:636-41.

38. Moore JS, Christensen M, Wilson RW, et al. Mycobacterial contamination of metal working fluids: Involvement of a possible new taxon of rapidly growing mycobacteria. Am Ind Hyg Assoc J 2000;61:205-13.

39. Rose CS, Martyny JW, Newman LS, et al. "Lifeguard Lung": Endemic granulomatous pneumonitis in an indoor swimming pool. Am J Publ Hlth 1998;88:1795-800.

40. Shelton BG, Flanders WD, Morris GK. Mycobacterium sp. as a possible cause of hypersensitivity pneumonitis in machine workers. Emerg Inf Dis 1999;5:270-3.

41. Martyny JW, Rose CS. Nontuberculous mycobacterial bioaerosols from indoor warm water sources cause granulomatous lung disease. Indoor Air 1999;9:1-6.

42. Rose CS, Martyny J, Huitt J, Iseman M. Hot tub associated granulomatous lung disease from mycobacterial aerosols. Am J Respir Crit Care Med 2000;161:A730.

43. Hüttunen K, Ruotsalainen M, Iivanainen E, Torkko P, Katila M-L, Hirvonen M-R. Inflammatory responses in RAW264.7 macrophages caused by mycobacteria isolated from moldy houses. Environ Toxicol Pharmacol 2000;8:237-44.

44. Howell JK, Lucke WE, Steigerwald JC. Metalworking fluids: Composition and use. AAMA Metalworking Fluids Symposium, Nov 13-16, 1996:13-20.

45. Guerin WF, Jones GE. Mineralization of phenanthrene by a Mycobacterium sp. Appl Environ Microbiol 1988;54:937-44.

46. Krulwich TA, Pelliccione NJ. Catabolic pathways of coryneforms, nocardias, and mycobacteria. Annu Rev Microbiol 1979;33:95-111. 
47. Best MS, Sattar SA, Springthorpe VA, Kennedy ME. Comparative mycobactericidal efficacy of chemical disinfectants in suspension and carrier tests. Appl Environ Microbiol 1988;54:2856-8.

48. Wilson, RW, Steingrube VA, Bottger EC, et al. Mycobacterium immunogenum sp. nov., a novel species related to Mycobacterium abscessus and associated with clinical disease, pseudo-outbreaks and contaminated metalworking fluids: An international cooperative study on mycobacterial taxonomy. Int J System Evol Microbiol 2001;51:1751-64.

49. Mangion EJ, Huitt G, Lenaway D, et al. Nontuberculous mycobacterial disease following hot tub exposure. Emerg Infect Dis 2001;7:1039-42

50. Embil J, Warren P, Yakrus M, Stark R, Corne S, Forrest D. Pulmonary illness associated with exposure to Mycobacterium avium complex in hot tub water: Hypersensitivity pneumonitis or infection? Chest 1997;111:813-6.

51. Kahana LM, Kay JM, Yakrus M, Waserman S. Mycobacterium avium complex infection in an immunocompetent young adult related to hot tub exposure. Chest 1997;111:242-5.
52. Arbeit RD, Slutsky A, Barber TW, et al. Genetic diversity among strains of Mycobacterium avium causing monoclonal and polyclonal bacteremia in patients with AIDS. J Infect Dis 1993;167:138-90.

53. Soini H, Eerola E, Viljanen MK. Genetic diversity among Mycobacterium avium complex AccuProbe-positive isolates. J Clin Microbiol 1996;34:55-7.

54. Dawson DJ. Infection with Mycobacterium avium complex in Australian patients with AIDS. Med J Austral 1990;153:466-8.

55. Covert TC, Rodgers MR, Reyes AL, Stelma GN Jr. Occurrence of nontuberculous mycobacteria in environmental samples. Appl Environ Microbiol 1999;65:2492-6.

56. Institute of Medicine. Microbial threats to health: Emergence, detection, and response. <www.iom.edu/report.asp?id=5381> (Version current at September 15, 2003).

57. Smith RA, Alexander RB, Wolman MG. Water-quality trends in the nation's rivers. Science 1987;235:1607-15.

58. du Moulin GC, Stottmeier KD, Pelletier PA, Tsang AY, Hedley-Whyte J. Concentration of Mycobacterium avium by hospital hot water systems. JAMA 1988;260:1599-601. 


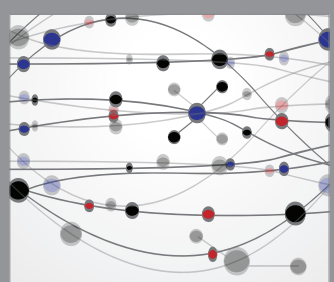

The Scientific World Journal
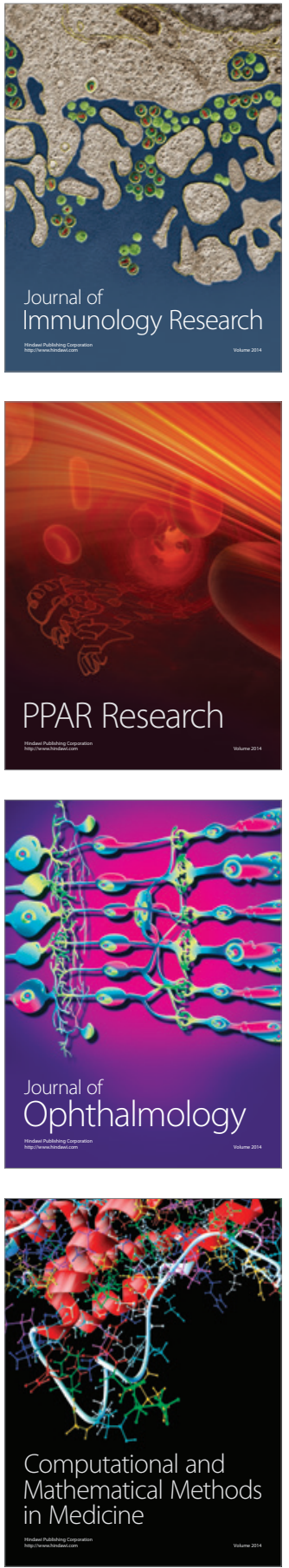

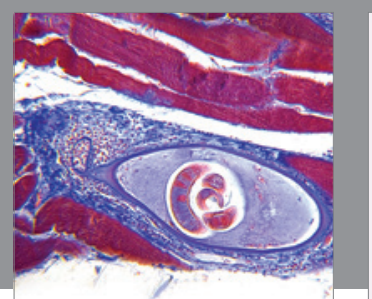

Gastroenterology Research and Practice

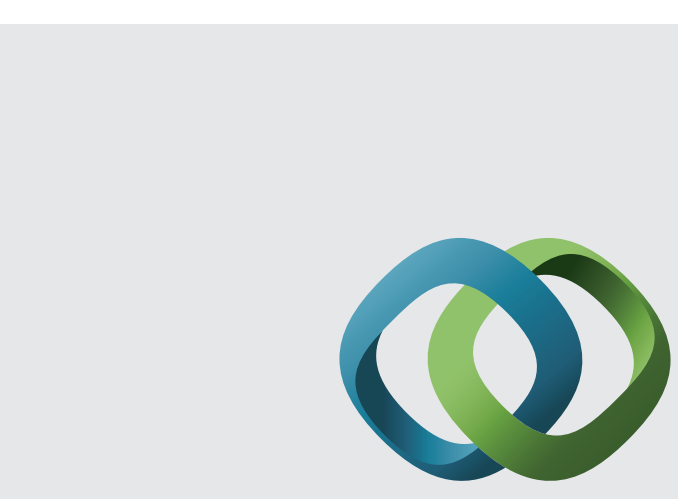

\section{Hindawi}

Submit your manuscripts at

http://www.hindawi.com
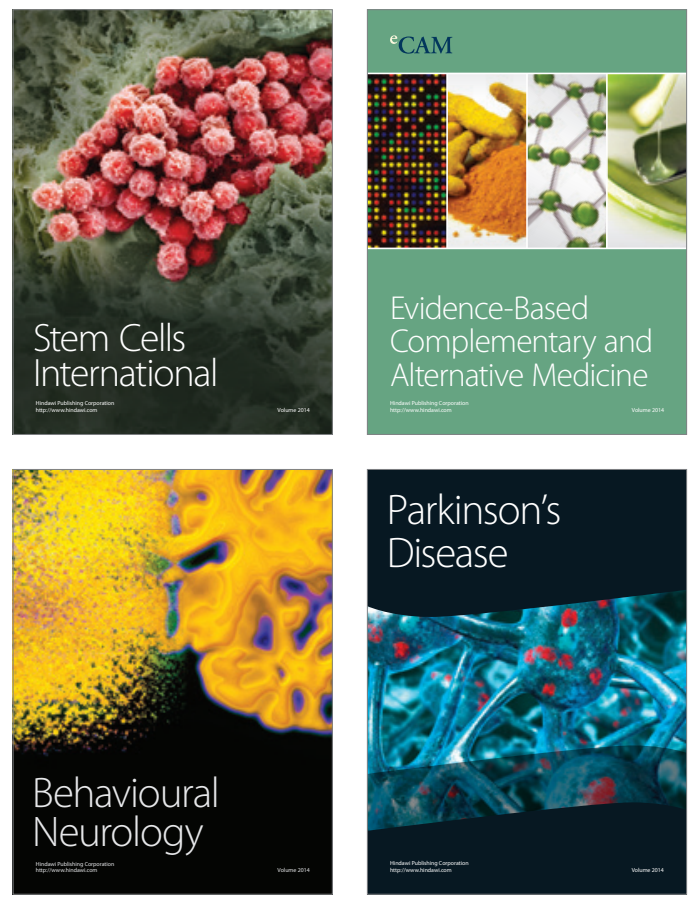
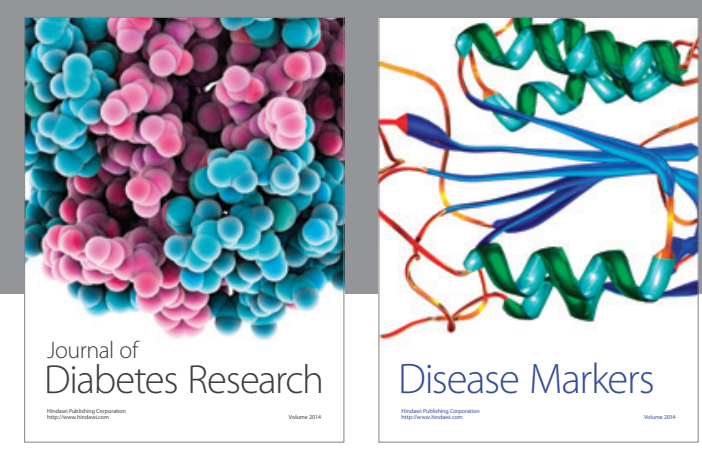

Disease Markers
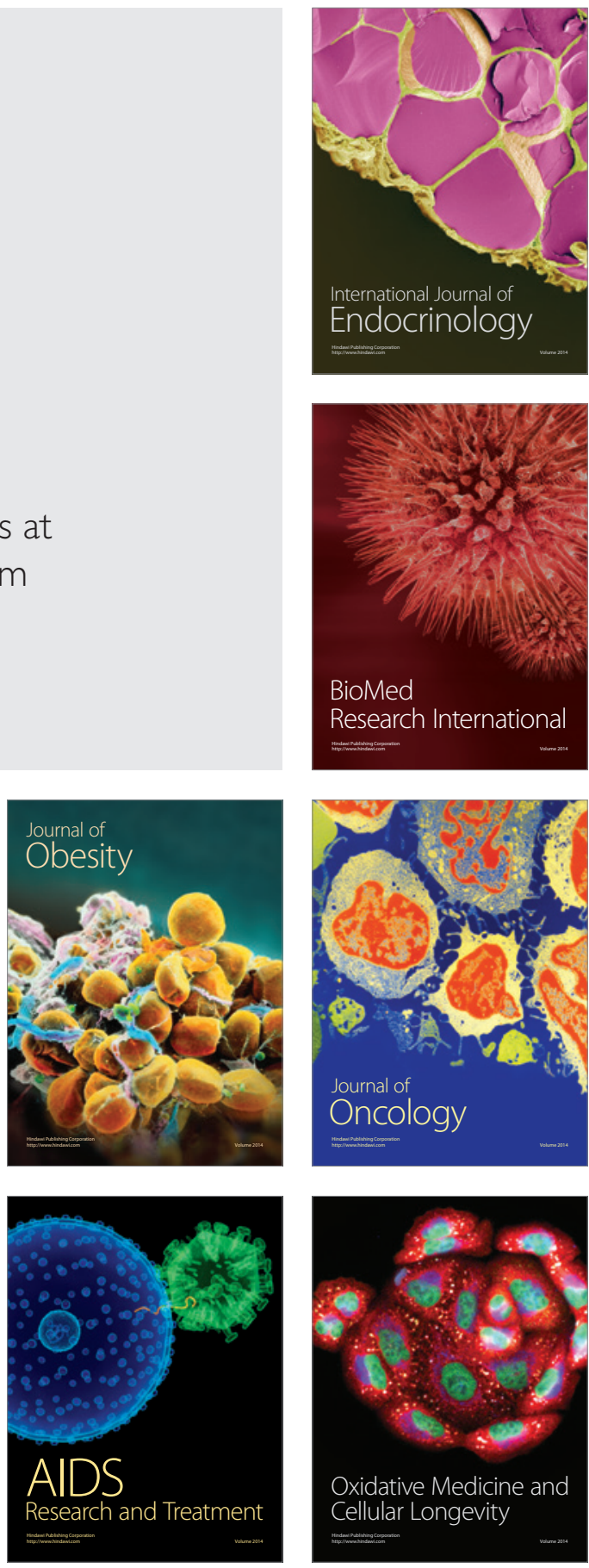